\title{
Leucine and isoleucine requirements of the kitten
}

\author{
BY DIANE M. HARGROVE, QUINTON R. ROGERS \\ AND JAMES G. MORRIS \\ Departments of Physiological Sciences and Animal Science, University of California, \\ Davis, California 95616, USA
}

(Received 16 January 1984 - Accepted 22 June 1984)

\begin{abstract}
1. In separate experiments the isoleucine and leucine requirements of the kitten were determined on the basis of growth and nitrogen retention. The dietary concentrations of isoleucine tested were ( $\mathrm{g} / \mathrm{kg} \mathrm{diet}) 1 \cdot 4,2 \cdot 2,3 \cdot 0$, $3.8,4.6$ and 9.0 with adequate $(12.0 \mathrm{~g} / \mathrm{kg}$ diet $)$ leucine. The levels of leucine tested were $(\mathrm{g} / \mathrm{kg} \mathrm{diet}) 5 \cdot 0,7 \cdot 5,9 \cdot 0$, $10.5,12.0$ and 20.0 in diets containing adequate $(9.0 \mathrm{~g} / \mathrm{kg}$ diet $)$ isoleucine. In both experiments six male and six female kittens received each dietary level of isoleucine or leucine for periods of $10 \mathrm{~d}$ in a balanced $6 \times 6$ Latin-square experimental design.

2. Asymptotic curves were fitted to the response relationships and the minimal dietary requirements for maximal response were estimated from the values at 0.95 of the asymptote. On this basis, the requirements for maximal growth were $6.2 \mathrm{~g}$ isoleucine $/ \mathrm{kg}$ and $7.8 \mathrm{~g}$ leucine $/ \mathrm{kg}$ diet. The requirements for maximal $\mathrm{N}$ retention were higher; $8.4 \mathrm{~g}$ isoleucine and $10.6 \mathrm{~g}$ leucine $/ \mathrm{kg}$ diet. The isoleucine requirements suggested by this method are probably overestimations and might be slightly above $4.6 \mathrm{~g} / \mathrm{kg}$ diet

3. Plasma isoleucine and leucine concentrations were not useful in estimating the requirements. Plasma leucine increased rectilinearly with increasing dietary leucine while the response of plasma isoleucine to increasing dietary isoleucine was non-rectilinear. Neither response relationship exhibited a breakpoint at the level of requirement. Below the suggested minimal requirement for leucine there were significant increases in the concentrations of isoleucine and valine in the plasma. Dietary isoleucine below the level of requirement had no effect on plasma valine and leucine. Dietary leucine had no effect on the plasma concentrations of methionine, phenylalanine and threonine, suggesting that the effect of decreasing dietary leucine on plasma isoleucine and valine is a result of decreased oxidation rather than decreased protein anabolism.

4. In a separate experiment six kittens, presented a diet containing $2 \cdot 2 \mathrm{~g}$ isoleucine $/ \mathrm{kg}$, developed crusty exudates around their eyes within $27 \mathrm{~d}$ and six kittens, presented diets containing $3.8 \mathrm{~g}$ isoleucine $/ \mathrm{kg}$, showed this clinical sign but with less severity within $47 \mathrm{~d}$. Cultures of conjunctival swabs taken from the most severely affected kittens showed the presence of staphylococcal species, suggesting that in isoleucine-deficient kittens there was impaired resistance to these dermal microbes.
\end{abstract}

The essentiality of leucine and isoleucine in the diet of growing kittens has been demonstrated by several investigators. Previous work (Rogers \& Morris, 1979) has shown that kittens switched from a basal diet containing $24 \mathrm{~g}$ leucine $/ \mathrm{kg}$ diet and $18 \mathrm{~g}$ isoleucine $/ \mathrm{kg}$ diet to diets devoid of either isoleucine or leucine had body-weight losses of 7.3 and $10.3 \mathrm{~g} / \mathrm{d}$ respectively. Anderson et al. (1980) reported that kittens given an isoleucine-free diet lost $7 \cdot 2 \mathrm{~g} / \mathrm{d}$.

The leucine and isoleucine requirements of the growing kitten have not been adquately established. Rogers \& Morris (1979) reported normal growth in kittens given diets containing $12.0 \mathrm{~g}$ leucine $/ \mathrm{kg}$ or $9.0 \mathrm{~g}$ isoleucine $/ \mathrm{kg}$. Anderson et al. (1980) reported no differences in weight gain and urinary nitrogen (\% of intake) between kittens given $3.0 \mathrm{~g}$ isoleucine $/ \mathrm{kg}$ diet and kittens given higher levels. However, because $3.0 \mathrm{~g}$ isoleucine $/ \mathrm{kg}$ diet is lower than the isoleucine requirement reported for other species they suggested $6.0 \mathrm{~g}$ isoleucine $/ \mathrm{kg}$ diet as the value that should be used for normal growth in kittens. In the same report they stated that the growth of kittens reached a plateau at $12.0 \mathrm{~g}$ leucine $/ \mathrm{kg}$ diet and suggested that $12.0 \mathrm{~g} / \mathrm{kg}$ was the dietary leucine requirement of kittens. The maximal gain of the kittens in the study by Anderson et al. (1980) was only $15 \mathrm{~g} / \mathrm{d}$, which is about half the potential body-weight gain of kittens.

The purpose of this report was to examine in more detail the isoleucine and leucine 
requirements of kittens growing near their maximal potential rate of gain, utilizing growth and $\mathrm{N}$ retention as indices. Also examined were the relationships between dietary isoleucine and leucine and plasma amino acid concentrations and the feasibility of using concentrations of plasma leucine and isoleucine to determine the requirements.

\section{METHODS}

In separate experiments, six male and six female specific-pathogen-free kittens received six dietary treatments for sequential $10 \mathrm{~d}$ periods in a balanced $6 \times 6$ Latin-square design. Purified diets that were isoenergetic and isonitrogenous containing $240 \mathrm{~g}$ crystalline amino acids $/ \mathrm{kg}$ were used. Details of sample collection and analysis have been described elsewhere (Hargrove et al. 1983). The diet used was the same as that described previously (Hargrove et al. 1983) except for the fat-soluble vitamins which comprised $(\mathrm{mg} / \mathrm{kg}$ diet $)$ : retinyl acetate 6.89 , cholecalciferol 0.05 , DL- $\alpha$-tocopherol 146 . The dietary levels of isoleucine tested $(\mathrm{g} / \mathrm{kg})$ were $1.4,2 \cdot 2,3 \cdot 0,3 \cdot 8,4 \cdot 6$ and $9 \cdot 0$ in diets containing adequate leucine $(12.0 \mathrm{~g} / \mathrm{kg})$. The leucine levels tested $(\mathrm{g} / \mathrm{kg}$ diet $)$ were $5 \cdot 0,7 \cdot 5,9 \cdot 0,10 \cdot 5,12 \cdot 0$ and $20 \cdot 0$ in diets containing adequate isoleucine $(9 \cdot 0 \mathrm{~g} / \mathrm{kg})$. Body-weights of the six male and six female kittens at the start of the experimental diets were $800-1400 \mathrm{~g}$.

During the course of the experiment to determine the isoleucine requirement, several kittens developed accumulations of a mucous discharge around their eyes, nose and lips. Since this clinical sign had not been observed in studies of deficiencies of other amino acids with specific pathogen-free kittens, isoleucine deficiency was suspected as the cause. However, because the experimental protocol required that the kittens received a different isoleucine level every $10 \mathrm{~d}$, it was difficult to relate this clinical sign to a given level of dietary isoleucine. To examine this condition further in relation to dietary isoleucine, a subsequent experiment was undertaken in which six kittens were given diets containing $2 \cdot 2 \mathrm{~g}$ isoleucine $/ \mathrm{kg}$ diet for 5 weeks and another group of six kittens was given a diet containing $3.8 \mathrm{~g}$ isoleucine $/ \mathrm{kg}$ diet for 8 weeks.

\section{Statistical analysis}

Data were subjected to analysis of variance appropriate for repeat Latin squares. When analysis of variance indicated significant $(P<0.05)$ differences in weight gain or $\mathrm{N}$ retention due to treatment, orthogonal comparisons (Steel \& Torrie, 1980) were performed to determine the nature of the response.

Asymptotic curves of the form $y=p_{1} \mathrm{e}^{p_{2} x}+p_{3}$ were fitted to the data for weight gain and $\mathrm{N}$ retention in the isoleucine study. A sigmoidal curve of the form $y=p_{1}+p_{2} /\left(1+\mathrm{e}^{p_{3}+p_{4} x}\right)$ was fitted to the $\mathrm{N}$ retention data from the leucine study. Because of the configuration of the response relationship, the sigmoidal curve gave less residual sum of squares than the asymptotic curve. The curves were fitted using the BMDP (1981) statistical software package program $3 \mathrm{R}$, where $x$ is the level of dietary isoleucine or leucine; $y$ is the weight gain or $\mathrm{N}$ retention; and $p_{1}, p_{2}, p_{3}$ and $p_{4}$ are constants. The nutrient concentrations at 0.95 of the asymptote (Robbins et al. 1979) were used as an estimate of the minimal requirement for maximal response. When analysis of variance indicated significant differences in food intake, the SNK multiple range test (Steel \& Torrie, 1980) was used to determine which means were statistically different.

\section{RESULTS}

\section{Isoleucine requirement}

The effect of dietary isoleucine on weight gain and $\mathrm{N}$ retention is summarized in Table 1. Weight gain and $\mathrm{N}$ retention exhibited a quadratic $(P<0.05)$ response relationship to increasing concentrations of dietary isoleucine. The response relationships and the fitted 
Table 1. Effect of dietary isoleucine level on weight gain and $N$ retention

(Mean values with their pooled standard errors for six kittens in the single sex groupings and for twelve kittens in the combined sex groups)

\begin{tabular}{|c|c|c|c|c|c|c|}
\hline \multirow{2}{*}{$\begin{array}{l}\text { Dietary } \\
\text { isoleucine } \\
\text { (g/kg diet) }\end{array}$} & \multicolumn{3}{|c|}{ Weight gain $(\mathrm{g} / \mathrm{d})$} & \multicolumn{3}{|c|}{$N$ retention $(\mathrm{g} / \mathrm{d})$} \\
\hline & Males & Females & $\begin{array}{c}\text { Sexes } \\
\text { combined }\end{array}$ & Males & Females & $\begin{array}{c}\text { Sexes } \\
\text { combined }\end{array}$ \\
\hline 1.4 & $2 \cdot 7$ & 1.5 & $2 \cdot 1$ & 0.21 & $0 \cdot 14$ & 0.17 \\
\hline $2 \cdot 2$ & $14 \cdot 0$ & $12 \cdot 8$ & $13 \cdot 4$ & 0.35 & 0.31 & 0.33 \\
\hline $3 \cdot 0$ & 23.9 & $23 \cdot 9$ & 23.9 & 0.64 & 0.52 & 0.58 \\
\hline $3 \cdot 8$ & $30 \cdot 1$ & $27 \cdot 5$ & $28 \cdot 8$ & 0.83 & 0.70 & 0.77 \\
\hline $4 \cdot 6$ & $33 \cdot 2$ & $28 \cdot 2$ & $30 \cdot 7$ & 0.92 & 0.75 & 0.84 \\
\hline $9 \cdot 0$ & $36 \cdot 4$ & $33 \cdot 6$ & $35 \cdot 0$ & 1.05 & 0.99 & 1.02 \\
\hline Pooled SE & 4.9 & $3 \cdot 4$ & $3 \cdot 0$ & 0.09 & 0.06 & 0.05 \\
\hline
\end{tabular}

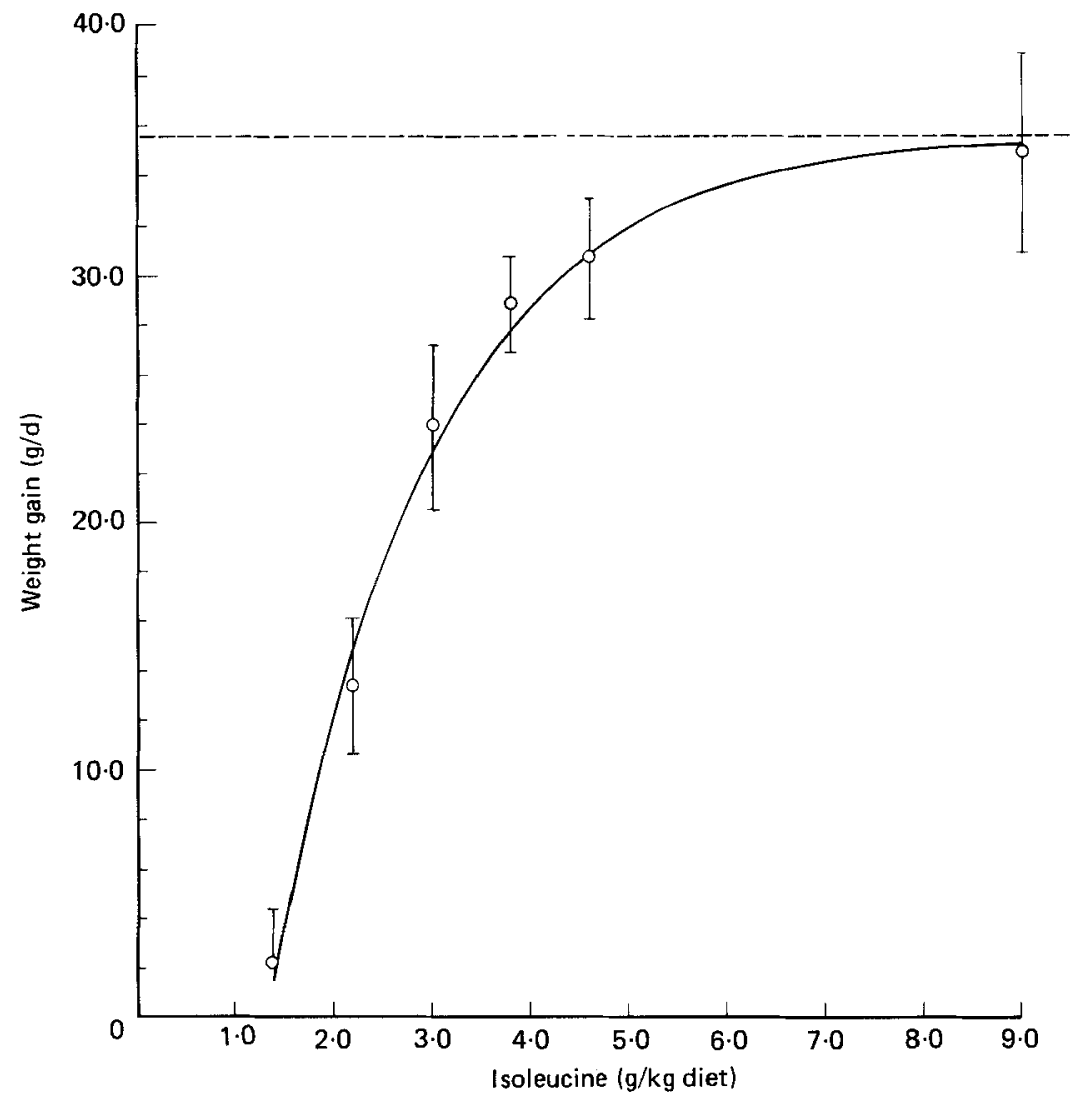

Fig. 1. The effect of dietary isoleucine on weight gain. Mean values with their standard errors represented by vertical bars for twelve kittens. The equation:

$$
\text { weight gain }=-80 \cdot 8 \mathrm{e}^{-0 \cdot 62 x}+35 \cdot 7
$$

is represented by the solid line. The dashed line is the asymptote. For details, see p. 596. 


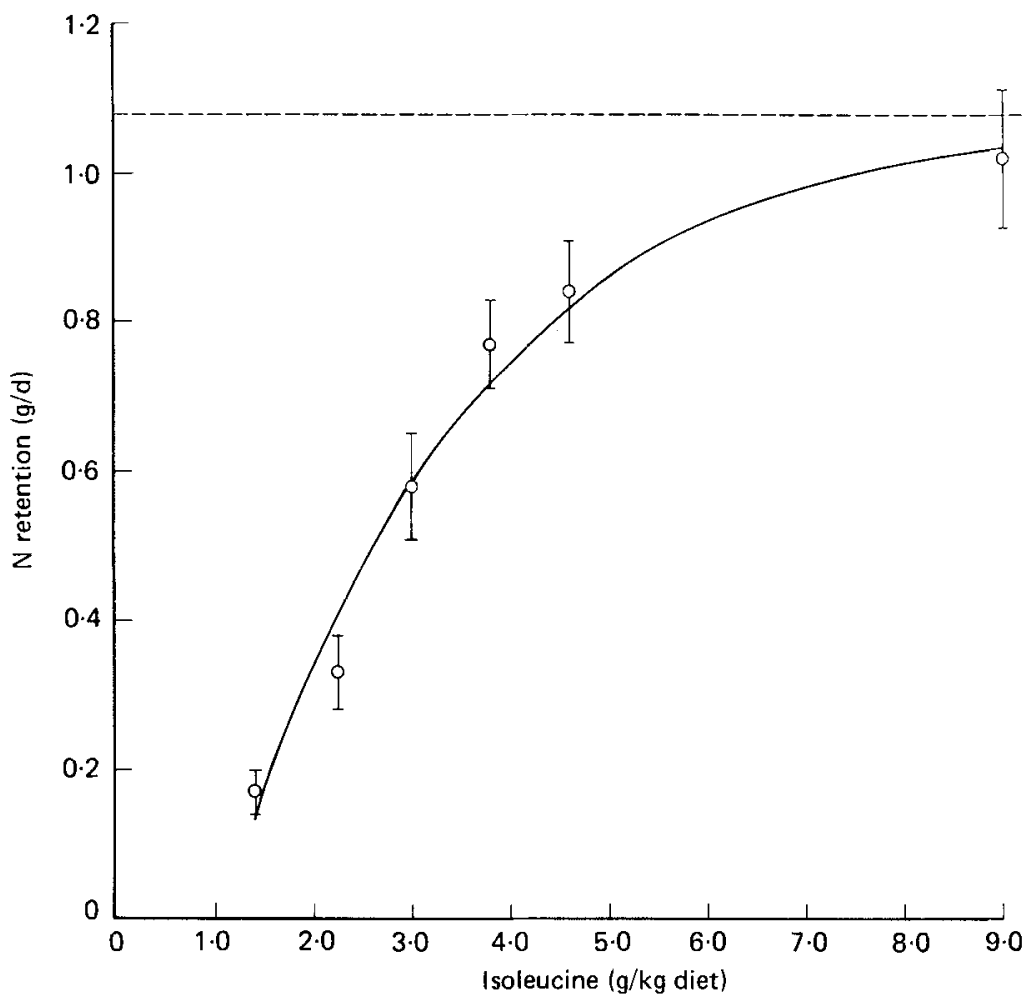

Fig. 2. The effect of dietary isoleucine on $\mathrm{N}$ retention. Mean values with their standard errors represented by vertical bars for twelve kittens. The equation:

$$
\mathrm{N} \text { retention }=-1.66 \mathrm{e}^{-0.41 x}+1.08
$$

is represented by the solid line. The dashed line is the asymptote. For details, see p. 596.

asymptotic curves for the sexes combined are plotted in Figs 1 and 2. The equations of the fitted curves were:

$$
\begin{aligned}
& \text { weight gain }=-80 \cdot 8 \mathrm{e}^{-0 \cdot 62 x}+35 \cdot 7 \quad\left(\text { SE for } p_{1}=7 \cdot 1, p_{2}=0 \cdot 06, p_{3}=1 \cdot 2\right) \\
& \mathrm{N} \text { retention }=-166 \mathrm{e}^{-0 \cdot 41 x}+1.08 \quad\left(\text { SE for } p_{1}=6 \cdot 0, p_{2}=0 \cdot 03, p_{3}=0.03\right)
\end{aligned}
$$

The dietary isoleucine concentrations at 0.95 of the asymptote were $6.2 \mathrm{~g} / \mathrm{kg}$ for weight gain and $8.4 \mathrm{~g} / \mathrm{kg}$ for $\mathrm{N}$ retention.

Dietary isoleucine had no effect $(P>0.05)$ on the food intake (Table 2$)$ of the male kittens; the females had a significantly lower food intake when consuming the diet containing the lowest level of isoleucine.

In a separate feeding study, six kittens (two females and four males), given a diet containing $2.2 \mathrm{~g}$ isoleucine $/ \mathrm{kg}$, all developed dried crusts around their eyes within $27 \mathrm{~d}$. One kitten exhibited this condition after consuming the diet for $4 \mathrm{~d}$ and another after $13 \mathrm{~d}$. Other clinical signs noted in these kittens included low daily weight gain of 15.5 (SE 2.8 ) g, crusting at the mucocutaneous junctions of the nose and mouth, peeling of pad epidermis, emprosthotonus, lethargy, slow righting reflex, inco-ordination and enlarged inguinal fat pads. Staphylcoccal species were cultured from the conjunctiva of the kittens with the most severe clinical signs, suggesting that isoleucine deficiency resulted in impaired resistance 
Table 2. Effect of dietary isoleucine level on food intake

(Mean values with their pooled standard errors for six kittens in the single sex groupings and for twelve kittens in the combined group)

\begin{tabular}{cccc}
\hline \hline $\begin{array}{c}\text { Dietary } \\
\text { isoleucine } \\
\text { (g/kg diet) }\end{array}$ & Males & Food intake $(\mathrm{g} / \mathrm{d})$ \\
\cline { 2 - 4 } & & & $\begin{array}{c}\text { Sexes } \\
\text { combined }\end{array}$ \\
\hline $1 \cdot 4$ & $66 \cdot 7^{\mathrm{a}}$ & $52 \cdot 0^{\mathrm{a}}$ & $59 \cdot 3^{\mathrm{a}}$ \\
$2 \cdot 2$ & $69 \cdot 2^{\mathrm{a}}$ & $63 \cdot 0^{\mathrm{b}}$ & $66 \cdot 1^{\mathrm{ab}}$ \\
$3 \cdot 0$ & $79 \cdot 9^{\mathrm{a}}$ & $66 \cdot 5^{\mathrm{b}}$ & $73 \cdot 2^{\mathrm{bc}}$ \\
$3 \cdot 8$ & $81 \cdot 1^{\mathrm{a}}$ & $74 \cdot 1^{\mathrm{b}}$ & $77 \cdot 6^{\mathrm{bc}}$ \\
$4 \cdot 6$ & $80 \cdot 0^{\mathrm{a}}$ & $70 \cdot 1^{\mathrm{b}}$ & $75 \cdot 0^{\mathrm{bc}}$ \\
$9 \cdot 0$ & $83 \cdot 9^{\mathrm{a}}$ & $79 \cdot 0^{\mathrm{b}}$ & $81 \cdot 4^{\mathrm{c}}$ \\
& $5 \cdot 5$ & $3 \cdot 7$ & $3 \cdot 3$ \\
\hline \hline
\end{tabular}

a,b, Values within the same sex grouping not sharing a common superscript are significantly different: $P<0.05$.

Table 3. Effect of dietary leucine level on weight gain and $N$ retention (Mean values with their pooled standard errors for six kittens in the single sex groupings and for twelve kittens in the combined sex group)

\begin{tabular}{|c|c|c|c|c|c|c|}
\hline \multirow{2}{*}{$\begin{array}{c}\text { Dietary } \\
\text { leucine } \\
\text { (g/kg diet) }\end{array}$} & \multicolumn{3}{|c|}{ Weight gain $(g / d)$} & \multicolumn{3}{|c|}{$\mathrm{N}$ retention $(\mathrm{g} / \mathrm{d})$} \\
\hline & Males & Females & $\begin{array}{c}\text { Sexes } \\
\text { combined }\end{array}$ & Males & Females & $\begin{array}{c}\text { Sexes } \\
\text { combined }\end{array}$ \\
\hline $5 \cdot 0$ & $24 \cdot 2$ & 18.9 & $21 \cdot 5$ & 0.62 & 0.56 & 0.59 \\
\hline 7.5 & 28.6 & 21.8 & $25 \cdot 2$ & 0.64 & 0.61 & 0.62 \\
\hline $9 \cdot 0$ & 34.9 & 30.8 & 32.9 & 0.88 & 0.77 & 0.83 \\
\hline $10 \cdot 5$ & 30.7 & $32 \cdot 4$ & 31.5 & 0.84 & 0.82 & 0.83 \\
\hline $12 \cdot 0$ & 33.9 & $22 \cdot 4$ & $28 \cdot 2$ & 1.01 & 0.76 & 0.89 \\
\hline $20 \cdot 0$ & $32 \cdot 3$ & $24 \cdot 0$ & 28.2 & 1.07 & 0.82 & 0.94 \\
\hline Pooled SE & 1.9 & $2 \cdot 2$ & 1.5 & 0.06 & 0.07 & 0.05 \\
\hline
\end{tabular}

to common dermal bacteria. After consuming the isoleucine-deficient diet $(2 \cdot 2 \mathrm{~g} / \mathrm{kg})$ for 5 weeks this group was offered an isoleucine-adequate diet $(9 \cdot 0 \mathrm{~g} / \mathrm{kg})$. Within 5 to $10 \mathrm{~d}$ all kittens improved markedly without other supportive therapy. Another group of kittens (three males and three females), given a diet containing $3.8 \mathrm{~g}$ isoleucine $/ \mathrm{kg}$ diet for 8 weeks, developed mild incrustations after consuming the diet for $47 \mathrm{~d}$.

\section{Leucine requirement}

The effect of dietary leucine on weight gain and $\mathrm{N}$ retention is summarized in Table 3 . Weight gain and $\mathrm{N}$ retention exhibited a quadratic $(P<0.05)$ response to increasing concentrations of dietary leucine. The equations of the fitted curves for the sexes combined were:

$$
\begin{aligned}
& \text { weight gain }=-188 \mathrm{e}^{-0 \cdot 62 x}+29 \cdot 8 \quad\left(\mathrm{SE} \text { for } p_{1}=174, p_{2}=0 \cdot 19, p_{3}=0 \cdot 5\right) \\
& \text { Nretention }=0 \cdot 56+0 \cdot 35 /\left(1+\mathrm{e}^{7 \cdot 8-91 \cdot 4 x}\right)\left(\text { SE for } p_{1}=0 \cdot 03, p_{2}=0 \cdot 04, p_{3}=2 \cdot 2, p_{4}=26 \cdot 9\right)
\end{aligned}
$$

The leucine requirements estimated from the concentrations at 0.95 of the asymptote were $7.8 \mathrm{~g} / \mathrm{kg}$ for weight gain and $10.6 \mathrm{~g} / \mathrm{kg}$ for $\mathrm{N}$ retention. 
Table 4. Effect of dietary leucine level on food intake

(Mean values with their pooled standard errors for six kittens in the single sex groupings and for twelve kittens in the combined group)

\begin{tabular}{|c|c|c|c|}
\hline \multirow{2}{*}{$\begin{array}{c}\text { Dietary } \\
\text { leucine } \\
\text { (g/kg diet) }\end{array}$} & \multicolumn{3}{|c|}{ Food intake $(\mathrm{g} / \mathrm{d})$} \\
\hline & Males & Females & $\begin{array}{c}\text { Sexes } \\
\text { combined }\end{array}$ \\
\hline $5 \cdot 0$ & $84 \cdot 0^{\mathrm{a}}$ & $72 \cdot 8^{\mathrm{a}}$ & $78 \cdot 4^{a}$ \\
\hline 7.5 & $80 \cdot 4^{\mathrm{a}}$ & $73 \cdot 2^{\mathrm{a}}$ & $76 \cdot 8^{\mathrm{a}}$ \\
\hline 9.0 & $87 \cdot 7^{\mathrm{a}}$ & $82 \cdot 8^{\mathrm{D}}$ & $85 \cdot 2^{b}$ \\
\hline $10 \cdot 5$ & $83 \cdot 1^{a}$ & $83 \cdot 4^{b}$ & $83 \cdot 3^{\mathrm{b}}$ \\
\hline $12 \cdot 0$ & $88 \cdot 1^{\mathrm{a}}$ & $78 \cdot 1^{\mathrm{ab}}$ & $83 \cdot 4^{b}$ \\
\hline $20 \cdot 0$ & $87 \cdot 7^{\mathrm{a}}$ & $79 \cdot 8^{\mathrm{ab}}$ & $83 \cdot 8^{\mathrm{b}}$ \\
\hline Pooled SE & $2 \cdot 1$ & $2 \cdot 1$ & $1 \cdot 5$ \\
\hline
\end{tabular}

a, $b$ Values within the same sex grouping not sharing a common superscript are significantly different: $P<0.05$.

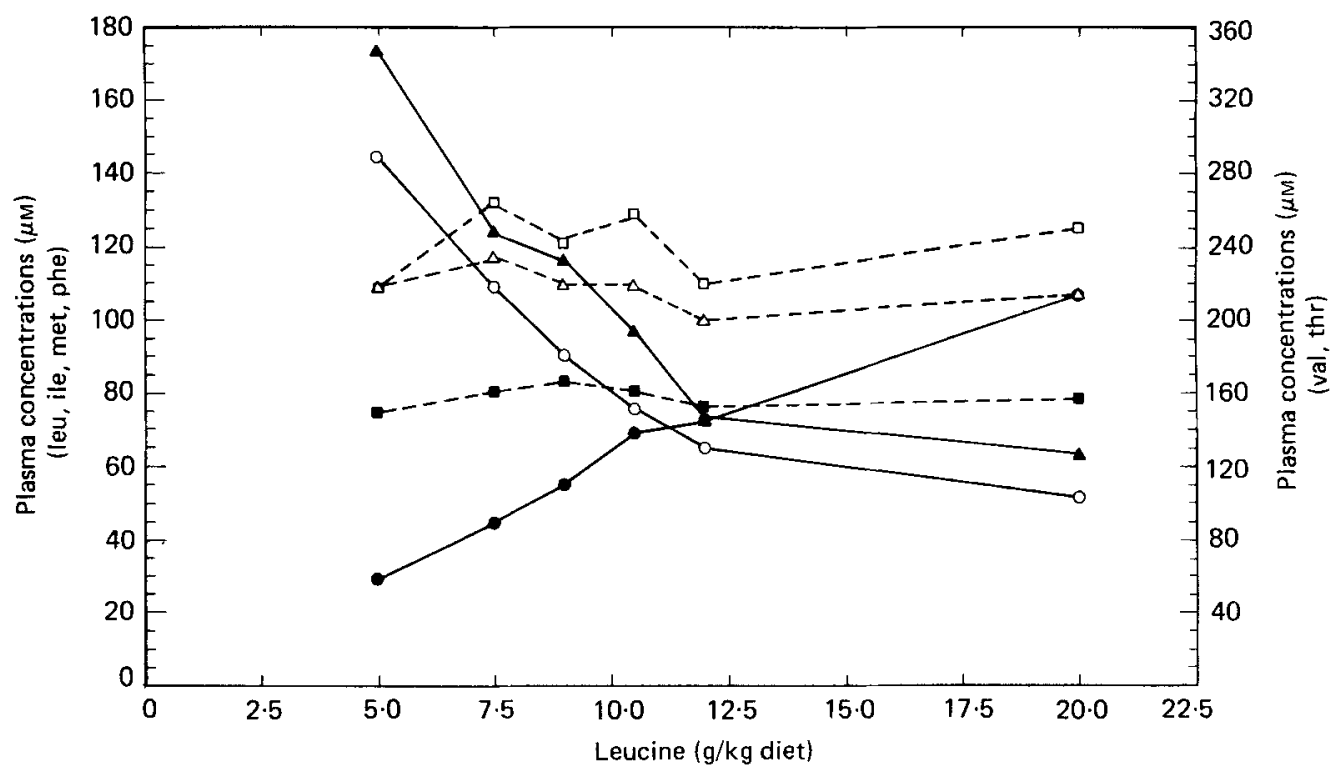

Fig. 3. The effect of dietary leucine on plasma amino acid concentrations. Points represent mean values for twelve kittens: $(O)$, isoleucine; $(\bullet)$, leucine; $(\square)$, methionine; $(\square)$, phenylalanine; $(\triangle)$, threonine; $(\boldsymbol{\Lambda})$, valine.

The level of dietary leucine had no effect $(P>0.05)$ on the food intake of the males (Table 4). In contrast, the food intake means of the females on the diets containing the two lowest levels of leucine were significantly $(P<0.05)$ less than on the diets containing 9.0 and $10.5 \mathrm{~g}$ leucine $/ \mathrm{kg}$.

\section{Plasma amino acids}

Plasma leucine concentration increased linearly $\left(r^{2} 0.97\right)$ in response to increasing dietary leucine. Plasma isoleucine and valine showed approximately three-fold increases when dietary leucine was decreased from 20.0 to $5.0 \mathrm{~g} / \mathrm{kg}$ (Fig. 3). Plasma concentrations of three other essential amino acids: methionine, phenylalanine and threonine, showed little change 


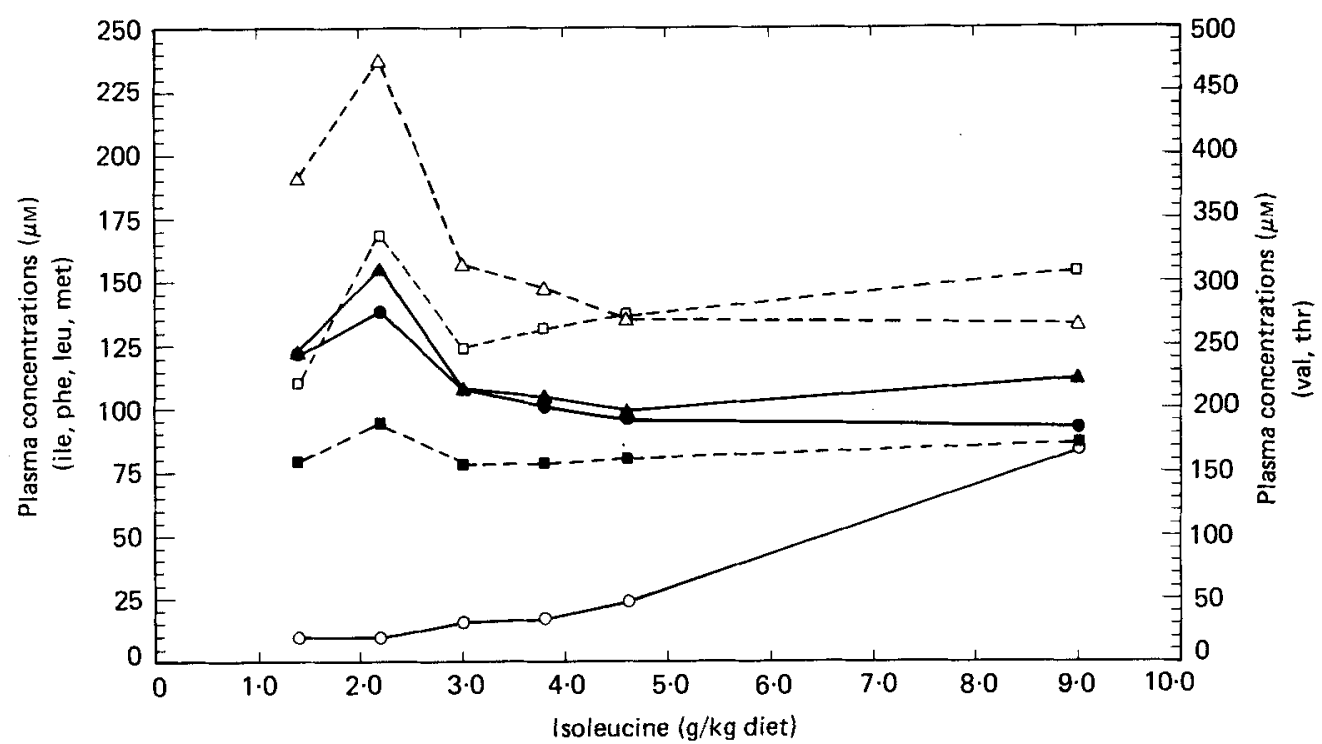

Fig. 4. The effect of dietary isoleucine on plasma amino acid concentrations. Points represent mean values for twelve kittens: $(O)$, isoleucine; $(\bigcirc)$, leucine; $(\square)$, methionine; $(\square)$, phenylalanine; $(\triangle)$, threonine; (A), valine.

(Fig. 3). The plasma tyrosine concentration decreased slightly as dietary leucine increased but not as markedly as the concentrations of plasma isoleucine and valine.

In contrast to dietary leucine, dietary isoleucine had very little effect on the plasma concentrations of the other branched chain amino acids (Fig. 4).Plasma leucine and valine concentrations showed a peak at $2.2 \mathrm{~g}$ isoleucine $/ \mathrm{kg}$ diet but otherwise showed no significant differences $(P>0 \cdot 05)$.

\section{DISCUSSION}

The dietary isoleucine requirements estimated from 0.95 of the asymptotes were 6.2 and $8.4 \mathrm{~g} / \mathrm{kg}$ for maximal growth and $\mathrm{N}$ retention respectively. These values, especially the one for $\mathrm{N}$ retention, probably overestimate the requirements. Maximal responses in weight gain and $\mathrm{N}$ retention occurred at the highest level of isoleucine tested $(9.0 \mathrm{~g} / \mathrm{kg}$ diet $)$. In part, this might be due to compensatory growth, particularly in the kittens which were changed from the diets containing the lowest levels of isoleucine to the diet containing $9 \cdot 0 \mathrm{~g} / \mathrm{kg}$. Evidence in support for this concern is that weight gains and $\mathrm{N}$ retentions of the kittens consuming the diet containing $9.0 \mathrm{~g}$ isoleucine $/ \mathrm{kg}$ were lower during the last $5 \mathrm{~d}$ of the $10 \mathrm{~d}$ experimental periods. At the second to highest level of isoleucine tested $(4.6 \mathrm{~g} / \mathrm{kg})$, the responses were $0.8-0.9$ of the maximum. As the dietary isoleucine concentration was approximately doubled, it is reasonable to suggest that the requirement is in the range of $4.6-9.0 \mathrm{~g} / \mathrm{kg}$ diet and closer to 4.6 than $9.0 \mathrm{~g} / \mathrm{kg}$. At $4.6 \mathrm{~g}$ isoleucine $/ \mathrm{kg}$ diet, the rates of change in the responses were rapidly decreasing, indicating that they were approaching their plateau values. Because the region of the plateau was defined largely by the responses at 4.6 and $9.0 \mathrm{~g} / \mathrm{kg}$ diet, and the responses at $9.0 \mathrm{~g}$ isoleucine $/ \mathrm{kg}$ diet may have been inflated, the fitted curves had shallow curvature (i.e. small absolute value for $p_{2}$ ) and probably exaggerated asymptotes. This problem was more pronounced for the $\mathrm{N}$ retention results because the incremental decreases in response between 3.0 and $4.6 \mathrm{~g}$ isoleucine $/ \mathrm{kg}$ diet were less than those for weight gain. As a result, the asymptote for $\mathrm{N}$ retention exceeded the 
maximal response by 0.06 times (Fig. 2) and the absolute value of $p_{2}$ for $\mathrm{N}$ retention was less than that for weight gain. Hence, the dietary isoleucine concentrations at 0.95 of the asymptotes of the fitted curves were probably in excess of the minimal requirements for maximal growth and $\mathrm{N}$ retention. The requirement may be slightly above $4.6 \mathrm{~g}$ isoleucine $/ \mathrm{kg}$ diet. These results are in contrast to those of Anderson et al. (1980) who reported no differences in growth and urinary $\mathrm{N}$ as a percentage of intake in kittens given diets containing $3 \cdot 0-10 \cdot 0 \mathrm{~g}$ isoleucine $/ \mathrm{kg}$ diet.

Isoleucine requirements for other species are lower than the one estimated by the method used here for the kitten. Dietary isoleucine levels $(\mathrm{g} / \mathrm{kg}$ ) of 5.0 (Rose, 1937), 5.5 (Rao et al. 1959) and 4.0 (Stockland \& Meade, 1970) have been reported as adequate for maximal growth in the rat. McLaughlan \& Illman (1967) reported $5.0 \mathrm{~g}$ isoleucine $/ \mathrm{kg}$ diet as the requirement of the rat, based on plasma isoleucine concentrations. Pick \& Meade (1971) have reported no improvement in growth and $\mathbf{N}$ retention when dietary isoleucine was increased from 3.6 to $5.6 \mathrm{~g} / \mathrm{kg}$ in the rat, suggesting the requirement may be $3.6 \mathrm{~g} / \mathrm{kg}$ diet or lower. John \& Bell (1976) demonstrated that $4.0 \mathrm{~g}$ isoleucine $/ \mathrm{kg}$ diet supported maximal growth in mice. Results reported by Bravo et al. (1970), using plasma isoleucine concentration in conjunction with $\mathrm{N}$ retention, suggest that the isoleucine requirement for $20-30 \mathrm{~kg}$ swine may be as low as $3.0 \mathrm{~g} / \mathrm{kg}$ diet. Mitchell et al. (1968) suggested 5.3 and $4.6 \mathrm{~g}$ isoleucine $/ \mathrm{kg}$ diet as the requirement of the young pig based on $\mathrm{N}$ retention and the breakpoint in plasma isoleucine respectively.

The mean weight gain of kittens given a diet containing $1.4 \mathrm{~g}$ isoleucine $/ \mathrm{kg}$ was $2 \cdot 1 \mathrm{~g} / \mathrm{d}$; some of the kittens lost body-weight and were in negative $\mathrm{N}$ balance. Kittens that received a diet containing $2.2 \mathrm{~g}$ isoleucine/ $\mathrm{kg}$ developed clinical signs which included secretions that dried into a crust around their eyes, nose and mouth, peeling of pad epidermis, lethargy, slowed righting reflex and enlarged inguinal fat pads. When the dietary isoleucine concentration was increased to $3.8 \mathrm{~g} / \mathrm{kg}$, kittens developed mild eye lesions within $47 \mathrm{~d}$. The occurrence of mucous exudate around the eyes of kittens given isoleucine-deficient diets appears to be specific to isoleucine. Kittens given diets deficient in the other essential amino acids have not exhibited this symptom. However, in the earlier reports (Hardy et al. 1977; Rogers \& Morris, 1979) the kittens used were not pathogen-free and possible respiratory infections may have masked deficiency signs with other essential amino acids. Teeter et al. (1978) noted similar clinical signs in specific pathogen-free cats given methionine-free diets. The relationship of these lesions to amino acid deficiencies and impaired resistance needs further investigation.

Kittens given diets containing $5.0 \mathrm{~g}$ leucine $/ \mathrm{kg}$ diet had submaximal weight gain and $\mathrm{N}$ retention. However, at this level of dietary leucine, $\mathrm{N}$ retention and growth were almost two-thirds of the maxima in both male and female kittens, resulting in dose response curves that had shallow slopes in comparison to those for other essential amino acids such as methionine (Schaeffer et al. 1982; Smalley et al. 1983) and tryptophan (Hargrove et al. 1983). Female kittens also showed exceptionally high weight gains on the diets containing 9.0 and $10 \cdot 5 \mathrm{~g}$ leucine $/ \mathrm{kg}$.

The leucine requirements estimated on the basis of the dietary concentrations at 0.95 of the asymptote were $7.8 \mathrm{~g} / \mathrm{kg}$ for growth and $10.6 \mathrm{~g} / \mathrm{kg}$ for $\mathrm{N}$ retention. The estimate based on $\mathrm{N}$ retention might be in excess because the male kittens, in contrast to the female kittens, did not exhibit maximal $\mathrm{N}$ retention until the dietary leucine concentration was in excess of $12.0 \mathrm{~g} / \mathrm{kg}$. When the female kittens were considered separately, the equation for the fitted curve was:

$$
\mathrm{N} \text { retention }=0 \cdot 56+0 \cdot 24 /\left(1+\mathrm{e}^{16 \cdot 3-2 \cdot 05 x}\right)
$$

and 0.95 of the asymptote occurred at $8.7 \mathrm{~g}$ leucine $/ \mathrm{kg}$ diet. This disparity in the requirement between growth and $\mathrm{N}$ retention due to differing responses of the sexes is 
unusual. In other amino acid requirement studies which we have conducted, the $\mathrm{N}$ retention results indicated requirements that were only slightly higher than those indicated by growth (Schaeffer et al. 1982; Hargrove et al. 1983; Smalley et al. 1983; D. D. Quam, J. M. Williams, Q. R. Rogers and J. G. Morris, unpublished results for histidine and phenylalanine requirements). Until further results are available, $10.6 \mathrm{~g}$ leucine $/ \mathrm{kg}$ diet is suggested as the minimal leucine requirement, even though the growth results and the $\mathrm{N}$ retention results for the females would suggest a lower requirement of $8.7 \mathrm{~g} / \mathrm{kg}$. The requirement indicated here is lower than the one reported by Anderson et al. (1980).

Leucine requirements reported for other species are similar to the one reported here for maximal growth in the kitten. For the rat, dietary leucine requirements of 9.0 and $6.9 \mathrm{~g}$ leucine/kg diet have been reported by Rose (1937) and Rao et al. (1959) using growth as the criterion. On the basis of plasma leucine concentration, McLaughlan \& Illman (1967) have reported a leucine requirement of $8.2 \mathrm{~g} / \mathrm{kg}$ diet. The (US) National Research Council (1978) suggested a value of $7.5 \mathrm{~g} / \mathrm{kg}$ diet as the minimal requirement for the rat. John \& Bell (1976) found $7.0 \mathrm{~g}$ leucine $/ \mathrm{kg}$ diet to be adequate for maximal growth in the mouse. A higher requirement of $14.2 \mathrm{~g} / \mathrm{kg}$ diet (D'Mello, 1975) has been reported for turkey poults. In swine, values ranging from 8.4 to $12.5 \mathrm{~g}$ leucine $/ \mathrm{kg}$ have been reported (Eggert $e t$ al. 1954; Williams et al. 1954; Mitchell et al. 1968).

Free plasma amino acid concentrations have been used under specified standardized conditions to estimate the dietary requirements for amino acids in some species. A sharp rise in the plasma amino acid concentration at the dietary requirement for that amino acid has been reported in chicks (Zimmerman \& Scott, 1965), swine (Mitchell et al. 1968; Bravo et al. 1970), rats (Morrison et al. 1961 ; Stockland et al. 1970; Young \& Munro, 1973) and humans (Young et al. 1971). McLaughlan \& Illman (1967) have successfully estimated amino acid requirements in rats by determining the dietary level of the amino acid which results in a plasma concentration of that amino acid equivalent to the fasting concentration for an adequately fed animal of the same species. Plasma leucine and isoleucine concentrations were not useful in estimating the isoleucine and leucine requirements of kittens. Plasma leucine increased linearly with increasing dietary leucine showing no breakpoint. Plasma isoleucine concentration did not show a clear breakpoint at the level of requirement. Attempts to use the method of McLaughlan \& Illman (1967), in which fasting plasma amino acids are used to estimate the requirement, results in values substantially higher than the requirements determined by growth and $\mathbf{N}$ retention. In our previous studies we found that plasma amino acids were of limited usefulness in estimating the amino acid requirements of the kitten (Schaeffer et al. 1982; Hargrove et al. 1983). Numerous factors have been shown to affect the plasma amino acid response including the daily feeding pattern (Stockland et al. 1970) and the feeding duration of the experimental diet (McLaughlan \& Illman, 1967; Mitchell et al. 1968). To minimize variations in time-since-last-meal, plasma samples were taken at the same time each sampling day. However, when food is available at all times, cats exhibit a random feeding pattern (Mugford \& Thorne, 1980; Kane et al. 1981). Variable intervals between sampling and the last meal may have contributed to variation in plasma amino acid patterns and so mitigated against their use in determing the requirement.

Decreasing dietary leucine from 20 to $5 \mathrm{~g} / \mathrm{kg}$ resulted in greater than three-fold increases in the plasma concentrations of the other branched-chain amino acids (BCAA). This effect has been reported in other species including chicks (Smith \& Austic, 1978), human infants (Synderman et al. 1968) and adults (Swendseid et al. 1965), swine (Mitchell et al. 1968), turkey poults (D'Mello, 1975) and rats (Rogers et al. 1962; Tannous et al. 1966; Clark et al. 1968). In the cat, leucine appears to be specific in its effects on the other two BCAA, since dietary isoleucine had very little effect on plasma valine and leucine concentrations, and Hardy et al. (1977) reported that, in kittens, dietary valine concentrations from 0 to 
$18 \mathrm{~g} / \mathrm{kg}$ diet had no effect on plasma isoleucine and leucine. The increases in plasma isoleucine and valine seen with decreasing dietary leucine could either be due to the reported role of leucine in BCAA metabolism (Frick \& Goodman, 1981; Paxton \& Harris, 1983) or protein anabolism (Buse \& Reid, 1975; Fulks et al. 1975; Buse \& Weigand, 1977; Li \& Jefferson, 1978). If the effect of leucine on plasma valine and isoleucine were due to protein anabolism, one would expect to see corresponding changes in the plasma concentrations of other essential amino acids. In this report, dietary leucine had no effect on plasma concentrations of methionine, phenylalanine and threonine suggesting that the changes in plasma isoleucine and valine were the result of the role of leucine in promoting oxidation of the BCAA rather than its role in protein anabolism.

The authors wish to thank Art Aguirre and John Bryan for their assistance with Kjeldahl and bomb calorimetry procedures, Dan Wong for assistance with plasma amino acid analysis, Ajinomoto Inc. USA for generously supplying part of the amino acids and Hoffman-LaRoche Inc. Nutley, New Jersey for providing the vitamin mixture. This research was supported in part by a grant from the Pet Food Institute, Washington DC.

\section{REFER ENCES}

Anderson, P. A., Baker, D. H., Sherry, P. A., Teeter, R. G. \& Corbin, J. E. (1980). Journal of Animal Science 50, 266-271.

BMDP (1981). BMDP statistical software. Los Angeles, California: Department of Biomathematics, University of California.

Bravo, F. O., Meade, R. J., Stockland, W. L. \& Nordstrum, J. W. (1970). Journal of Ánimal Science 31, $1137-1141$.

Buse, M. G. \& Reid, S. S. (1975). Journal of Clinical Investigation 56, 1250-1261.

Buse, M. G. \& Weigand, D. A. (1977). Biochimica et Biophysica Acta 475, 81-89.

Chua, B., Siel, D. L. \& Morgan, H. E. (1979). Journal of Biological Chemistry 254, 8358-8362.

Clark, A. J., Yamada, C. \& Swendseid, M. E. (1968). American Journal of Physiology 215, 1324-1328.

D'Mello, J. P. F. (1975). British Poultry Science 16, 607-615.

Eggert, R. G., Williams, H. H., Sheffy, B. E., Sprague, E. G., Loosi, J. K. \& Maynard, L. A. (1954). Journal of Nutrition 53, 177-185.

Frick, G. P. \& Goodman, H. M. (1981). In Metabolism and Clinical Implications of Branch Chain Amino and Ketoacids, pp. 73-78 [M. Walser \& J. R. Williamson, editors]. New York: Elsevier North Holland Inc.

Fulks, R. M., Li, J. B. \& Goldberg, A. L. (1975). Journal of Biological Chemistry 250, 290-298.

Hardy, A. J., Morris, J. G. \& Rogers, Q. R. (1977). Journal of Nutrition 107, 1308-1312.

Hargrove, D. M., Rogers, Q. R. \& Morris, J. G. (1983). British Journal of Nutrition 50, 487-493.

John, A. M. \& Bell, J. M. (1976). Journal of Nutrition 106, 1361-1368.

Kane, E., Rogers, Q. R., Morris, J. G. \& Leung, P. M. B. (1981). Nutrition Research 1, 499-507.

Li, J. B. \& Jefferson, L. S. (1978). Biochimica et Biophysica Acta 544, 351-359.

McLaughlan, J. M. \& Illman, W. I. (1967). Journal of Nutrition 93, 21-24.

Mitchell, J. R. Jr, Becker, D. E., Jensen, A. H., Harmon, B. G. \& Norton, H. W. (1968). Journal of Animal Science 27, 1327-1331.

Morrison, A. B., Middleton, E. J. \& McLaughlan, J. M. (1961). Canadian Journal of Biochemistry and Physiology 39, $1675-1680$.

Mugford, R. A. \& Thorne, C. (1980). In Nutrition of the Dog and Cat, pp. 3-14 [R. S. Anderson, editor]. Oxford: Pergamon Press.

National Research Council (1978). Nutrient Requirements of Domestic Animals No. 10, Nutrient Requirements of Laboratory Animals, 3rd Revised ed. Washington DC: National Academy of Science-National Research Council.

Paxton, R. \& Harris, R. A. (1983). Proceedings of the American Societies for Experimental Biology Abstracts 42 , 540.

Pick, R. T. \& Meade, R. J. (1971). Journal of Nutrition 101, 1241-1248.

Rao, P. B. R., Metta, V. C. \& Johnson, B. C. (1959). Journal of Nutrition 69, 387-391.

Robbins, K. R., Norton, H. W. \& Baker, D. H. (1979). Journal of Nutrition 109, 1710-1714.

Rogers, Q. R. \& Morris, J. G. (1979). Journal of Nutrition 109, 718-723.

Rogers, Q. R., Spolter, P. D. \& Harper, A. E. (1962). Archives of Biochemistry and Biophysics 97, $497-504$.

Rose, W. C. (1937). Science 86, 298-300.

Schaeffer, M. C., Rogers, Q. R. \& Morris, J. G. (1982). Journal of Nutrition 112, 962-971. 
Smalley, K. A., Rogers, Q. R. \& Morris, J. G. (1983). British Journal of Nutrition 49, 411-417.

Smith, T. K. \& Austic, R. E. (1978). Journal of Nutrition 108, 1180-1191.

Steel, R. G. D. \& Torrie, J. H. (1980). Principles and Procedures of Statistics. New York: McGraw-Hill Book Company.

Stockland, W. L. \& Meade, R. J. (1970). Journal of Animal Science 31, 1156-1167.

Stockland, W. L., Meade, R. J. \& Melliere, A. L. (1970). Journal of Nutrition 100, 925-933.

Swendseid, M. E., Villalobos, J., Figueroa, W. S. \& Drenick, E. J. (1965). American Journal of Clinical Nutrition 17, 317-321.

Synderman, S. E., Holt, L. E. Jr, Norton, P. M. \& Roitman, E. (1968). Protein Nutrition and Free Amino Acid Patterns, pp. 19-31 [J. H. Leathem, editor]. New Brunswick N.J.: Rutgers University Press.

Tannous, R. I., Rogers, Q. R. \& Harper, A. E. (1966). Archives of Biochemistry and Biophysics 113, 356-361.

Teeter, R. G., Baker, D. H. \& Corbin, J. E. (1978). Journal of Animal Science 46, 1287-1292.

Williams, H. H., Curtin, L. V., Abraham, J., Loosi, J. K. \& Maynard, L. A. (1954). Journal of Biological Chemistry 208, 277-286.

Young, V. R., Hussien, M. A., Murray, E. \& Scrimshaw, N. S. (1971). Journal of Nutrition 101, 45 -59.

Young, V. R. \& Munro, H. N. (1973). Journal of Nutrition 103, 1756-1763.

Zimmerman, R. A. \& Scott, H. M. (1965). Journal of Nutrition 87, 13-18. 